\title{
Posterior fossa subdural haematomas
}

\author{
JOHN MILES AND A. V. MEDLERY ${ }^{1}$ \\ From the Regional Department of Medical and Surgical Neurology, \\ Walton Hospital, Liverpool
}

SYNOPSIS Traumatic posterior fossa subdural haematomas are rare and, while part of a major head injury, may give little warning of their presence. A definite proportion of cases will be well enough to exhibit progressive and recognizable posterior fossa signs that might include occipital headache, raised intracranial pressure, lateralized cerebellar or brain-stem signs, and a fracture of the occipital bone. These cases will be readily amenable to investigation and cure by evacuation of the causative haematoma.

The management of the severe head injury must be directed towards predicting and preventing complications that would further aggravate the existing state of injury. It is in just such a connotation that one often considers the threat of an occult posterior fossa haematoma. This anxiety finds support in the reports of Fisher et al. (1958) and Ciembroniewicz (1965) in which little warning and no specific signs heralded fatal deterioration in the presence of posterior fossa subdural haematomas. In the posterior fossa, these subdural haematomas proved equally as bad as extradural haematomas. Against this background of such a sinister reputation, and together with the acknowledged rarity of posterior fossa subdural haematoma, we have recently been relieved and pleasantly surprised in respect of two encounters with this condition. The presentation in each case took a clinically recognized form and the evolution was of such relative benignity that specific investigation, operation, and a satisfactory outcome resulted.

\section{CASE 1}

(S.D.: 31927/71) An 11 year old boy was flung from a swing 13 days before admission to our unit. He had struck the back of his head and was admitted to another hospital where he was said to be unconscious for three days and had a post-traumatic amnesia of four days. He had no laceration, but radiological examination of the skull showed a vertical linear fracture in the left occipital bone pass-

1 Present address: St John's Medical College, Bangalore 34, India. ing the full length of the posterior fossa. Twelve hours after admission he suffered a generalized convulsion, but by 10 days he had become fully alert, uncomplaining, and active about the ward. From 10 to 13 days after the accident he complained of progressively increasing occipital headache and vomited.

On examination at this time he was alert, orientated, and only slightly distressed. He had early papilloedema, nystagmus on each lateral gaze, together with slight incoordination of the right limbs and Rombergism. There was no meningism.

Selective vertebral angiography was undertaken and clearly demonstrated the suspected right posterior fossa extracerebellar collection (Figs 1 and 2). Under the same anaesthetic, the posterior fossa was explored and a high pressure, black, fluid subdural haematoma was evacuated. There was a fine filamentous capsule to the haematoma, but no obvious source for bleeding from the cerebellum or from the overlying bone and there was no fracture of the right occipital bone. He made a prompt and uneventful recovery, having only a little nystagmus evident 10 days after operation when he was discharged home. He had no symptoms and no signs at followup, one month and one year later.

\section{CASE 2}

(A.R.J.: 35332/72) An 18 year old male student crashed his motor cycle five days before transfer to this unit. He struck the back of his helmeted head on the road and was briefly unconscious with a posttraumatic amnesia of a few minutes. When admitted to another hospital, he was drowsy but orientated and free from abnormal neurological signs and had no laceration of the scalp. Radiographs showed a 

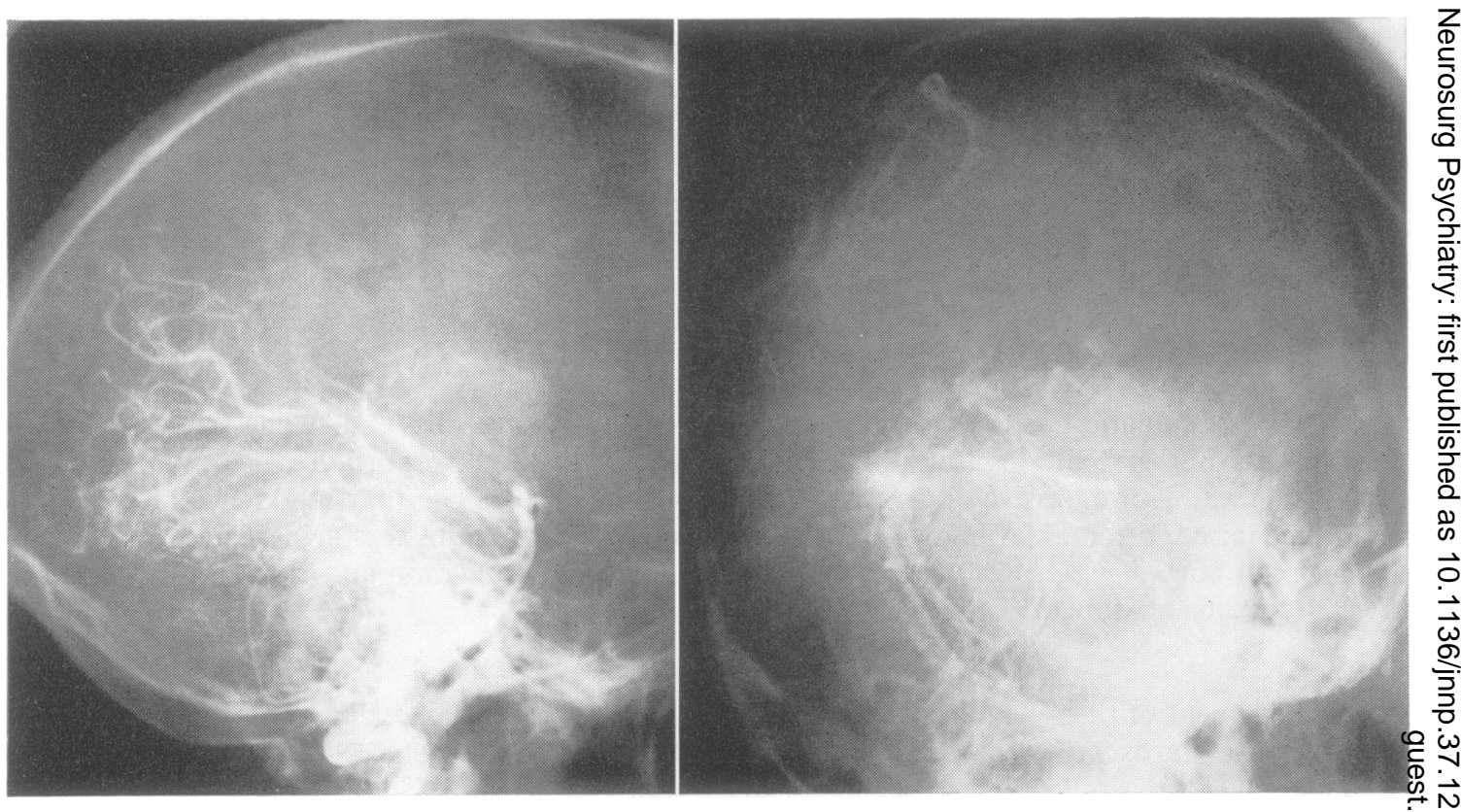

FIG. 1 (left) Case 1. Lateral view of the vertebral angiogram, showing an avascular extracerebellar space occupying lesion. FIG. 2 (right) Case 1. Right oblique film of vertebral angiogram showing the same surfaceD $\omega$ collection.
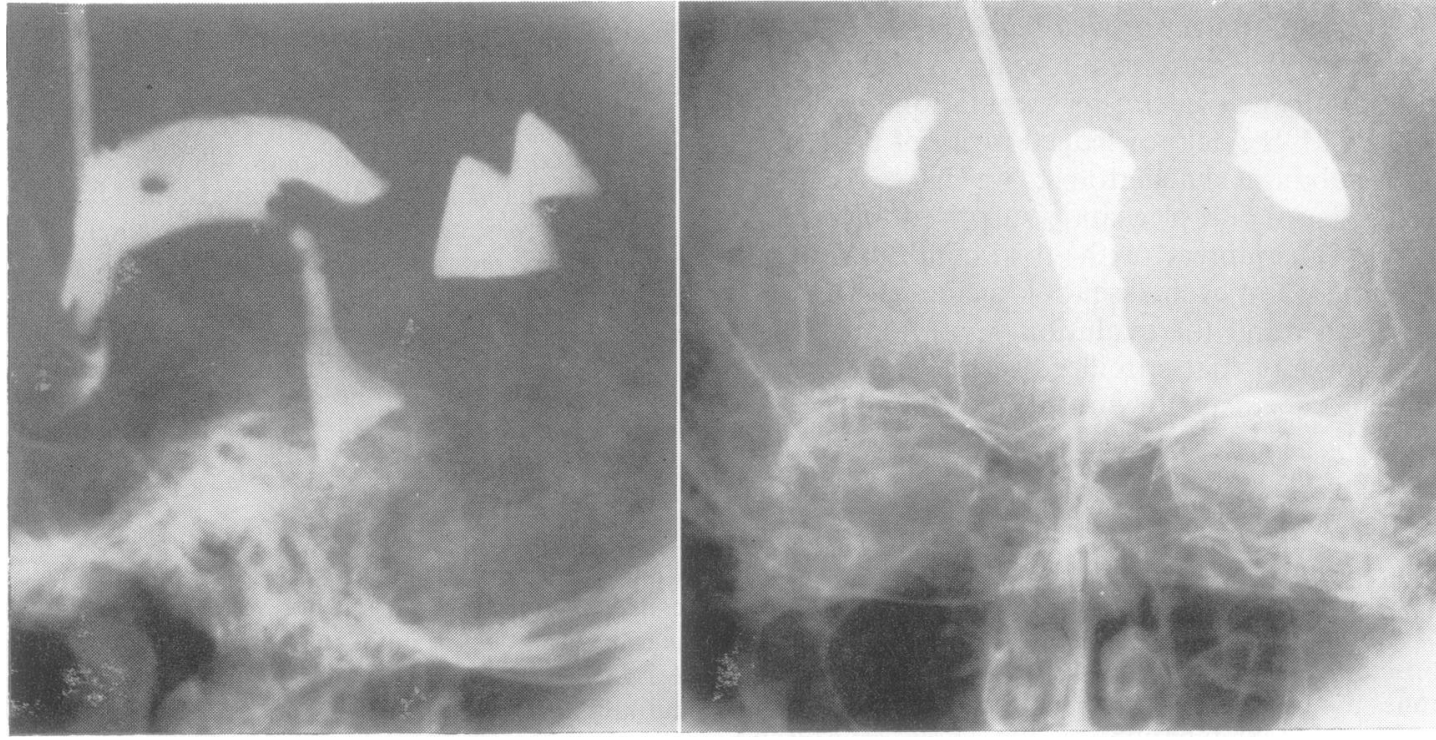

FIG. 3 (left) Case 2. Iophendylate ventriculogram, lateral view. FIG. 4 (right) Case 2. Ventriculogram showing lateral displacement of the fourth ventricle to the left. 
vertical linear fracture of the left occipital bone in the posterior fossa. Over the next two days, except for slight neck stiffness, he appeared well but then complained of progressively increasing headache with diplopia and mild photophobia.

On examination, four days after the injury, he was distressed, with headache, slight diplopia due to a minimal right sixth nerve paresis, early papilloedema, horizontal nystagmus on each lateral gaze, weakness of the right palate, and mild incoordination of the right limbs. Pulse and blood pressure were normal.

Selective vertebral angiography, for technical reasons, was less than satisfactory and did not confirm the suspected right posterior fossa haematoma. Over the next six days, he continued to complain of headache and his papilloedema increased, despite a regime including dexamethasone. The sixth nerve paresis first became complete and then gradually recovered, while the palatal palsy and incoordination remained minimal.

A brain scan, including a posteroanterior projection was normal. Eleven days after the injury, a right frontal burr hole revealed the brain and the ventricular cerebrospinal fluid to be under high pressure. Ventriculography with iophendylate (Myodil) showed displacement of the fourth ventricle forward (Fig. 3), and to the left (Fig. 4).

Right posterior fossa exploration revealed a rightsided high pressure, black, fluid subdural haematoma, posterior and superolateral to the right cerebellar hemisphere. It appeared to have arisen from a contusion of the inferolateral aspect of this hemisphere.

The symptoms and signs cleared until mobilization when the patient exhibited severe postural, and presumably labyrinthine, vertigo with vomiting and nystagmus that gradually resolved with prochlorperazine. At follow-up three months, one, and two years later he was totally free from symptoms and signs.

\section{DISCUSSION}

Subdural haematomas of the posterior fossa are rare. Ciarla (1913), in 6,631 routine necropsies, discovered 57 subdural haematomas, one of which was in the posterior fossa. McKissock et al. (1960) described two posterior fossa subdural haematomas in a series of 389 intracranial subdural haematomas. Ciembroniewicz (1964), found three in a total of 535 intracranial subdural haematomas and Wright (1966), described five in a total of 361 intracranial haematomas. In the 26 years, 1947 to 1973 , in this unit, there have been 418 subdural haematomas of which only the two cases here reported are considered to be true subdural haematomas of the posterior fossa. In two other cases there was extensive supratentorial, subtemporal haematoma extending over the clivus as a significant amount of prepontine subdural haematoma.

Clitherow et al. (1969), from this unit, described another case of combined cerebellar and subdural haematoma. In most series, subdural, extradural, and intracerebellar posterior fossa haematomas have been found with approximately equal frequency (Fisher et al., 1958; Wright, 1966).

When there has been a severe injury to the posterior fossa, and considering the accepted extreme vulnerability of the medulla to compression in such circumstances, it is understandable that rapid deterioration with high mortality could result from a concomitant subdural haematoma (Fisher et al., 1958; Ciembroniewicz, 1964; Wright, 1966). However, an extended survival, as an expression of the limited nature of the original injury, would seem to be important in allowing the evolution of a recognizable neurological syndrome, its investigation, and successful treatment. Neisser and Pollack (1904), when describing the first successfully treated case of posterior fossa subdural haematoma, noted the presentation as ataxia in a history extending for three months and mentioned also two other cases diagnosed at necropsy but having, in life, manifest cerebellar signs. Their cases were operated on 13 and 11 days after trauma. Yamashita et al. (1971), operated on the posterior fossa of his case 10 days after trauma with successful outcome. Fisher's two surviving cases were operated on eight and three days after trauma, while the one that died was only one day after injury. The two fatal cases described by Wright were less than two days after trauma while the survivors were five, seven, and 28 days after trauma. Again, Ciembroniewicz (1964) had two fatal cases 24 hours after trauma, while the third survived when operated upon seven days after trauma. The importance of the limited nature of the trauma is emphasized in each of our cases in that both were well enough to complain of increasing occipital headache and, in one case, of diplopia.

Ciembroniewicz (1964) analysed the 26 cases that had been reported in the literature and added three of his own. Neurological signs 
played such a little part in his analysis that there was not even a column for them in the otherwise very full table summarizing the salient features. His three cases all deteriorated rapidly with decerebration suggestive of coning without lateralized neurological signs, but four of the cases reviewed, in fact, had nystagmus, and two ataxia. None of the five cases of Wright (1966) had cerebellar signs and neither did that of Yamashita et al. (1971). Both of our cases had recognizable and lateralizing hind brain signs though, in each case, although the nystagmus was prominent, the incoordination was mild. The second case also had a sixth nerve and palatal palsy on the side of the haematoma.

Clitherow et al. (1969) reported from this unit a unique case of combined intracerebellar and subdural haematoma in which the patient passed through a stage of cerebellar signs into coma and they concluded that the initial cerebellar signs resulted from the intracerebellar haematoma which later ruptured into the subdural space. It is perhaps also possible that the subdural haematoma itself contributed to the neurological signs before their obscuration by deterioration.

Yamashita et al. (1971) illustrate another form of presentation-namely, a failure to improve from deep coma after evacuation of a supratentorial haematoma. Posterior fossa investigation was undertaken and cure obtained by evacuation of an additional subdural haematoma there.

The mortality in the reported cases has been quite high. Ciembroniewicz (1964) noted a mortality of nine out of the 26 cases analysed; eight out of 20 where definite trauma had occurred, and one out of six where there was no history of trauma.

\section{INVESTIGATIONS}

SKULL RADIOGRAPH The occipital bone was fractured in six out of the 17 cases analysed by Ciembroniewicz (1964); three out of the five cases described by Wright (1966), and in both of ours. We are at a loss to explain the fact that in each of our cases the fracture was on the side opposite to the haematoma without any evidence, at operation, that the fracture had extended across the mid-line. We know of no suggestion of a contre-coup effect being possible across the posterior fossa.

LUMBAR PUNCTURE If a posterior fossa haematoma is suspected, this investigation should be strictly prohibited, but, in fact, survey of the reported cases shows it regularly to have been undertaken and xanthochromia commonly found (Ciembroniewicz, 1964; Wright, 1966). In one of our cases, a lumbar puncture had been performed before we were consulted, and again xathochromia was noted. It would seem just as likely that this was indicative of an incidental traumatic subarachnoid haemorrhage.

ANGIOGRAPHY Carotid angiography might be useful in showing ventricular dilatation but vertebral angiography has proved diagnostic in the case of Yamashita et al. (1971) and in our first case. Our second case, however, illustrates that poor quality angiography might not prove effective and in fact positively delayed treatment of the condition. Ventriculography proved effective in this case but should be used only if angiography fails.

BRAIN SCAN We were disappointed that a brain scan did not prove effective, while we acknowledged the difficulty in obtaining a satisfactory posteroanterior projection for investigation of the posterior fossa.

\section{PATHOLOGY}

The source of bleeding has been from the cerebellar cortex in two of the three cases reported by Ciembroniewicz (1964), in one of our cases, and in that reported by Clitherow et al. (1969). Frequently, no obvious source has been found. Again, it is to be noted that the fracture was on the opposite side in both our cases.

\section{TREATMENT}

Lateral craniectomy would seem satisfactory treatment. We also removed the posterior lip of the foramen magnum and the posterior arch of the atlas as an insurance against medullary compression due to postoperative oedema. 


\section{REFERENCES}

Ciarla, E. (1913). Beitrag zum pathologisch-anatomischen und klinischen Studium der Pachymeningitis cerebralis haemorrhagica. Archiv für Psychiatrie und Nervenkrankheiten, 52, 439-491.

Ciembroniewicz, J. E. (1965). Subdural hematoma of the posterior fossa. Journal of Neurosurgery, 22, 465-473.

Clitherow, N. R., Fowler, A., and Sedzimir, C. B. (1969). Combined intracerebellar and posterior fossa subdural hematomas. Journal of Neurosurgery, 30, 744-746.

Fisher, R. G., Kim, J. K., and Sachs, E., Jr (1958). Complications in the posterior fossa due to occipital trauma. Journal of the American Medical Association, 167, 176-182.
McKissock, W., Richardson, A., and Bloom, W. H. (1960). Subdural haematoma. A review of 389 cases. Lancet, 1 1365-1369.

Neisser, E., and Pollack, K. (1904). Die Hirnpunktion. Probepunktion und Punktion des Gehirnes und seiner Häute durch den intakten Schädel. Mitteilungen aus den Grenzgebieten der Medizin und Chirurgie, 13, 807-896.

Wright, R. L. (1966). Traumatic hematomas of the posterior cranial fossa. Journal of Neurosurgery, 25, 402-409.

Yamashita, J., Yoshida, Y., Togo, M., Watanabe, T., and Fukumitsu, T. (1971). Traumatic subdural hematoma of the posterior fossa: case report. Brain and Nerve, 23, 813817. 